\title{
Testicular Leukemia
}

National Cancer Institute

\section{Source}

National Cancer Institute. Testicular Leukemia. NCI Thesaurus. Code C9277.

A myeloid or more commonly lymphoid leukemia (acute or chronic) affecting the testis.

Microscopically, there is interstitial infiltration of the testis by leukemic cells. Acute

lymphoblastic leukemia with testicular involvement is not uncommon in boys. Sometimes

(up to $10 \%$ of the cases), testicular involvement may be the initial manifestation of

relapsed acute lymphoblastic leukemia. --03 